\title{
Brief report: coronary heart disease: an unknown association to pathological gambling
}

\section{Candice Germain ${ }^{1}$,Alec Vahanian', Anne Basquin' ${ }^{1}$, Charlotte Richoux-Benhaim ${ }^{3}$, Houcine Embouazza' and Michel Lejoyeux ${ }^{1,3 *}$}

1 Department of Psychiatry, Maison Blanche Hospital, Paris, France

2 Department of Cardiology, Bichat Hospital, Assistance Publique - Hôpitaux de Paris, Paris, France

${ }^{3}$ Department of Psychiatry, Bichat Hospital, Assistance Publique - Hôpitaux de Paris, Paris, France

\section{Edited by:}

Alain Dervaux, Centre Hospitalier

Sainte-Anne, France

Reviewed by:

Semion G. Kertzman, Tel Aviv

University, Israel

Florence Thibaut, University of

Medicine, France

Aviv Weinstein, Hebrew University

Hospital, Israel

Fatima El Omari, MohammedV

University of Rabat, Arrazi University

Hospital of Rabat-Salé, Morocco

\section{*Correspondence:}

Michel Lejoyeux, Department of Psychiatry, Hospital Bichat Claude

Bernard, Assistance Publique -

Hôpitaux de Paris, 75877 Paris CEDEX

18, France.

e-mail:michel.lejoyeux@bch.aphp.fr
Pathological gamblers (PG), because of their high level of stress, depression, and alcohol or nicotine consumption may be overexposed to coronary heart disease (CHD). To test this association, we assessed pathological gambling (DSM-IV-TR criteria and South Oaks Gambling Screen scale) among 73 patients hospitalized in cardiology for CHD and 61 in-patients from the same department hospitalized for a non-coronary disorder. We found six cases of PG (8.2\%) and one case of problem gambling in the CHD group versus no case in the non-coronary group $(p=0.01)$. Pathological gambling was not associated to a higher level of alcohol or nicotine consumption neither to a higher level of sensation-seeking.

Keywords: gambling, coronary heart disease, alcohol, nicotine, stress

\section{INTRODUCTION}

Pathological gamblers (PG) share many psychological characteristics with coronary heart disease (CHD). They tend to increased dependence to alcohol and cocaine (Mutschler et al., 2010), higher levels of depression and anxiety, and experiment stress during and after gambling whatever they lose or win (Lejoyeux et al., 2002). Their hypothalamic-pituitary-adrenal axis is more activated and their salivary cortisol increases in response to gambling stimuli (Franco et al., 2010). Another risk factor for CHD in PGs is smoking (Petry and Oncken, 2002) or second-hand smoke exposure (Shaffer et al., 1999). They suffer more often than controls from "stress," fatigue, insomnia, respiratory ailments, intestinal distress, headaches, high blood pressure, and cardiovascular diseases (Larimer et al., 2006). A previous study (NESARC) found a link between CHD and pathological gambling. PGs were more likely than low-risk individuals to have been diagnosed with angina $(\mathrm{OR}=2.35 ; 95 \% \mathrm{CI}=1.33-4.15$; Morasco et al., 2006). The association is particularly frequent in the older patients, as the patients assessed in the present study (Pietrzak et al., 2007). Potenza et al. (2002) also suggested a link between casino gambling and cardiac arrest. We tried to confirm the hypothesis that PGs, because of their high level of stress, depression, alcohol and nicotine consumption, are more exposed to CHD. The aim of our study was to know if PGs have a higher risk of CHD. We compared for this purpose gambling activity among in-patients from a department of cardiology presenting or not CHD.

\section{MATERIALS AND METHODS \\ SUBJECTS}

All consecutive patients (73) hospitalized for a CHD in the department of cardiology of Bichat hospital (Paris, France) were assessed by a psychiatrist (Candice Germain) and a psychologist (Charlotte Richoux-Benhaim or Anne Basquin). Controls (61 patients) were recruited at the same time in the same department of cardiology among patients who did not present CHD. Thirty were hospitalized for heart failure not induced by a CHD, 16 for valvulopathy, and 15 for severe hypertension. Seventeen patients refused the assessment (nine in the CHD group and eight in the control group). We did not pre-select a population of patients, either for the CHD or the control group.

\section{INSTRUMENTS}

Data were collected between February and June 2009 from direct interviews. Before beginning the study, we tested the validity and the reliability of the questionnaire in 20 subjects. All parts of the questionnaire consisted of standardized scales previously validated (Saliou et al., 2005).

\section{ASSESSMENT OF PROBLEM AND PATHOLOGICAL GAMBLING}

The South Oaks Gambling Screen (SOGS) evaluated gambling behavior (Lesieur and Blume, 1987) with 20 items on lifetime gambling and allowed for classification as non-gambler or recreational gambler, problem gambler or probable PG. We checked in addition the DSM-IV-R criteria for pathological gambling with a 
standardized interview previously used and validated (Lejoyeux et al., 1999). Patients were asked about their frequency of gambling in the last year and about the amount of money spent on gambling during their all life. We used a standardized questionnaire assessing the amount of money spent in gambling during all life (Lejoyeux et al., 1999).

\section{ALCOHOL AND NICOTINE USE AND ABUSE DISORDERS}

All subjects answered the Cut - Annoyed, Guilty - Eye opener (CAGE) questionnaire on alcohol consumption (Ewing, 1984) and another questionnaire on the number of drinks of alcoholic beverage taken each day, the number of days per week in which drinking had occurred during the last month. A drink was defined as the amount of alcohol found in $300 \mathrm{ml}$ of beer, $100 \mathrm{ml}$ of wine, or $25 \mathrm{ml}$ of whisky. Cigaret smoking was studied with the Fagerström questionnaire (Fagerström and Schneider, 1989).

\section{PSYCHIATRIC STATE AND SENSATION-SEEKING}

Anxiety and depression were assessed with the General Health Questionnaire (Goldberg and Blackwell, 1970). Finally, patients filled in a French version of the Zuckerman Sensation-seeking scale (Zuckerman, 1999).

For all parameters we compared patients with or without CHD. For categorical data, differences were studied with the $\chi^{2}$-test and for continuous variables with the unpaired two-tailed Student's $t$-tests. Statistical significance was determined at the 0.05 level of confidence.

\section{RESULTS AND DISCUSSION}

Mean age was equivalent in the two groups: 64.8 years. We did not find difference between the two groups (CHD+ and $\mathrm{CHD}-$ ) for education level, marital and work status, alcohol and nicotine consumption. Scores at the CAGE, Fagerström, GHQ, and Zuckerman questionnaires were also equal. We found six cases of pathological gambling $(8.2 \%)$ and one case of problem gambling in the CHD group versus no case in the non-coronary group $\left(\chi^{2}=5.2, d f=1\right.$, $p=0.02)$. All the six gamblers with SOGS score equal or higher than five fulfilled the DSM-IV-R criteria for pathological gambling. Gamblers had bet 806 euros in their life versus 222 euros in nongamblers $(t=2.5, \mathrm{~d} f=132, p=0.01)$. No patient with pathological gambling received a treatment for gambling and none of the gamblers was treated with psychotropic drugs (Table 1).

Interpretation of our results is limited by the small number of patients included. This observation needs to be confirmed in a larger population. Another limitation of our work is that patients with CHD were compared with in-patients from the same department of cardiology who were not "true controls." Retrospective assessment of the amount of money spent in gambling during all life may be imprecise if patients do not remember all their gambling experiences.

In spite of all its limitations, our study suggests an association between pathological gambling and CHD (9.6 vs 0\% in the CHD group). Physiopathological hypothesis can be suggested to explain this association. Previous studies in gamblers reported increases in heart rate (Meyer et al., 2000) and higher levels of noradrenergic

Table 1 | Pathological and problem gambling among patients hospitalized in cardiology for a coronary heart disease (CHD).

\begin{tabular}{|c|c|c|c|c|c|c|c|}
\hline \multirow[t]{2}{*}{ Characteristics } & \multicolumn{2}{|c|}{ CHD $(N=73)$} & \multicolumn{2}{|c|}{ Controls $(N=61)$} & \multicolumn{3}{|c|}{ Statistics } \\
\hline & $N$ & $\%$ & $N$ & $\%$ & $\chi^{2}$ & $d f$ & $p$ \\
\hline Problem gamblers & 1 & 1.3 & 0 & 0 & 0.84 & 1 & 0.359 \\
\hline Pathological gamblers & 6 & 8.22 & 0 & 0 & 5.2 & 1 & 0.02 \\
\hline \multirow[t]{2}{*}{ Problem + pathological gamblers } & 7 & 9.6 & 0 & 0 & 6.1 & 1 & 0.01 \\
\hline & MEAN & SD & MEAN & SD & $t$ & $d f$ & $p$ \\
\hline SOGS scores & 0.9 & 2.6 & 0.09 & 0.35 & 2.3 & 132 & 0.02 \\
\hline \multicolumn{8}{|l|}{ Money spent during the life in } \\
\hline gambling (in euros) & 969 & 2742 & 509 & 1881 & 0.9 & 132 & 0.34 \\
\hline \multicolumn{8}{|l|}{ Alcohol consumption } \\
\hline Drinks/day & 1.3 & 1.5 & 1.6 & 2.3 & -0.8 & 132 & 0.4 \\
\hline Drinking days/week & 3.2 & 3 & 2.7 & 3.1 & 0.9 & 132 & 0.3 \\
\hline Acute alcohol intoxication/month & 0.09 & 0.8 & 0.04 & 0.2 & 0.4 & 132 & 0.66 \\
\hline CAGE score & 0.7 & 1.1 & 0.6 & 1.1 & 0.4 & 132 & 0.64 \\
\hline \multicolumn{8}{|l|}{ Nicotine consumption } \\
\hline Cigarets/day & 3.1 & 7.2 & 3.2 & 8.6 & -0.07 & 132 & 0.93 \\
\hline Day/week with cigaret & 1.4 & 2.8 & 1.2 & 2.7 & 0.3 & 132 & 0.73 \\
\hline Fagerström score & 1.3 & 2.7 & 1.3 & 2.8 & 0.03 & 132 & 0.97 \\
\hline General Health Questionnaire & 3.3 & 3.1 & 3.4 & 3 & -0.16 & 132 & 0.87 \\
\hline Zuckerman scale general factor & 13.6 & 7.4 & 12.7 & 6.1 & 0.7 & 132 & 0.44 \\
\hline Disinhibition & 2.5 & 2 & 2 & 1.6 & 1.5 & 132 & 0.11 \\
\hline Danger-adventure seeking & 4.1 & 2.9 & 3.9 & 3 & 0.3 & 132 & 0.7 \\
\hline Experience seeking & 4.6 & 2.1 & 4.4 & 2.1 & 0.5 & 132 & 0.55 \\
\hline Boredom susceptibility & 2.2 & 1.9 & 2.3 & 1.7 & -0.16 & 132 & 0.86 \\
\hline
\end{tabular}

Bold = statistically significant 
metabolites (Roy et al., 1988). PGs also present higher level of anxiety (Grant and Potenza, 2006). Other confounding risk factors such as tobacco use, lipid status, and hypertension may explain the association between gambling and CHD.

From another point of view, we did not find different levels of sensation-seeking in gamblers with or without CHD. Correlations have been observed between Type A behavior, cardiac reactivity, and the risk if CHD (Shahidi et al., 1991). No study, however, showed that a high level of sensation-seeking is associated with an increased risk of CHD. The question of sensation-seeking in-patients with pathological gambling is also controversial, especially in French studies which did not find higher levels of sensation-seeking among PGs (Allcock and Grace, 1988; Coventry and Brown, 1993; Bonnaire et al., 2004, 2007; Saez-Abad and Bertolin-Guillen, 2008; Fortune

\section{REFERENCES}

Allcock, C. C., and Grace, D. M. (1988). Pathological gamblers are neither impulsive nor sensation-seekers. Aust. N. Z. J. Psychiatry 22, 307-311.

Bonnaire, C., Lejoyeux, M., and Dardennes, R. (2004). Sensation seeking in a French population of pathological gamblers: comparison with regular and non gamblers. Psychol. Rep. 94(Pt 2), 1361.

Bonnaire, C., Varescon, I., and Bungener, C. (2007). Recherche de sensations dans une population française de joueurs de courses de chevaux: comparaison entre des joueurs pathologiques et réguliers. L'Encéphale 33, 798-804.

Coventry, K. R., and Brown, F. I. R. (1993). Sensation seeking, gambling and gambling addictions. Addiction 88, 541-554.

Ewing, J. A. (1984). Detecting alcoholism: the CAGE questionnaire. JAMA 252, 1905.

Fagerström, K. O., and Schneider, N. G. (1989). Measuring nicotine dependence: a review of the Fagerström Tolerance Questionnaire. J. Behav. Med. 12, 159-182.

Fortune, E. E., and Goodie, A. S. (2010). The relationship between pathological gambling and sensation seeking: the role of subscale scores. J. Gambl. Stud. 26, 331-346.

Franco, C., Paris, J. J., Wulfert, E., and Frye, C. (2010). Male gamblers have significantly greater salivary cortisol before and after betting on horse race than do female gamblers. Physiol. Behav. 99, 225-229.

Goldberg, D. P., and Blackwell, B. (1970). Psychiatric illness in general practice. A detailed study using a new method of case identification. Br. Med. J. 1 439-443.

Grant, J. E., and Potenza, M. N. (2006). Escitalopram treatment of pathological gambling with co-occurring anxiety: an open-label pilot study with double-blind discontinuation. Int. Clin. Psychopharmacol. 21, 203-209.

Larimer, M. E., Lostutter, T. W., and Neighbors, C. (2006). Gambling in primary care patients: what should we care and what can we do about it? Gen. Hosp. Psychiatry 28, 89-91.

Lejoyeux, M.,Arbaretaz, M., Mc Loughlin, M., and Adès, J. (2002). Impulse control disorders and depression. J. Nerv. Ment. Dis. 190, 310-314.

Lejoyeux, M., Feuché, N., Loi, S., Solomon, J., and Adès, J. (1999). Study of impulse control disorders among alcoholdependent patients. J. Clin. Psychiatry 40, 302-305.

Lesieur, H. R., and Blume, S. B. (1987). The South Oaks Gambling Screen: a new instrument for the identification of pathological gamblers. Am. J. Psychiatry 144, 1184-1188.

Meyer, G., Hauffa, B. P., Schedlowski, M., Pawlak, C., Stadler, M. A., AND Exton, M.S. (2000). Casino gambling increases heart rate and salivary cortisol in regular gamblers. Biol. Psychiatry 48, 948-953.

Morasco, B. J., Pietrzak, R. H., Blanco, C., Grant, B. F., Hasin, D., and Petry, N.M. (2006). Health problems and medical utilization associated with gambling disorders: results from the national epidemiologic survey on alcohol and related conditions. Psychosom. Med. 68, 976-984.

Mutschler, J., Bühler, M., Diehl,A., Mann, K., and Kiefer, F. (2010). Disulfiram,

and Goodie, 2010). Association between high level of sensationseeking and pathological gambling is still more controversial in older patients like those included in our study (mean age: 64.8 years old).

In clinical practice, our observation may incite to more systematically check the cardiac state of PGs and to be more vigilant to their risk of CHD especially when they smoke or present a high level of stress. These results also support assessing gambling behavior among CHD patients.

\section{ACKNOWLEDGMENT}

The study was reviewed and approved by the institutional review board of the department. All patients participated voluntarily in the study and provided written informed consent. To ensure confidentiality, all identifying data were removed and all records were kept locked.

an old drug with new potential in the treatment of pathological gambling? Med. Hypotheses 74, 209-210.

Petry, N. M., and Oncken, C. (2002) Cigarette smoking is associated with increased severity of gambling problems in treatment-seeking gamblers. Addiction 97, 745-753.

Pietrzak, R. H., Morasco, B. J., Blanco, C., Grant, B. F., and Petry, N. (2007) Gambling level and psychiatric and medical disorders in older adults: results from the national epidemiologic survey on alcohol and related conditions. Am. J. Geriatr. Psychiatry 15, 301-313.

Potenza, M. N., Fiellin, D. A., Heninger, G. R., Rounsaville, B. J., and Mazure, C. M. (2002). Gambling: an addictive behavior with health and primary care implications. J. Gen. Intern. Med. 17, 721-732.

Roy, A., Adinoff, B., Roehrich, L., Lamparski, D., Custer, R., Lorenz, V. Barbaccia, M., Guidotti, A., Costa, E., and Linnoila, M. (1988). Pathological gambling a psychobiological study. Arch. Gen. Psychiatry 45, 369-373.

Saez-Abad, C., and Bertolin-Guillen, J. M.(2008). Personality traits and disorders in pathological gamblers versus normal controls. J. Addict. Dis. 27, 33-40.

Saliou, V., Fichelle, A., Mc Loughlin, M. Thauvin, I., and Lejoyeux, M. (2005). Psychiatric disorders among patients admitted to a French medical emergency service. Gen. Hosp. Psychiatry 27, 263-268.

Shaffer, H. J., Vander Bilt, J., and Hall, M. N. (1999). Gambling, drinking, smoking and other health risk activities among casino employees. Am. J. Ind. Med. 36, 365-378.
Shahidi, S., Henley, S., Willows, J., and Furnham, A. (1991). Type A behaviour pattern: the effect of competition on heart rate and performance on a driving game. Pers. Individ. Dif. 12, 1277-1282.

Zuckerman, M. (1999). "Substance abuse and dependence and pathological gambling disorders," in Chapter 6, Vulnerability to Psychopathology. A Biopsychosocial Model, ed M. Zuckerman (Washington: American Psychological Association), 255-317.

Conflict of Interest Statement: The authors declare that the research was conducted in the absence of any commercial or financial relationships that could be construed as a potential conflict of interest.

Received: 23 September 2010; paper pending published: 18 February 2011; accepted: 02 March 2011; published online: 16 March 2011.

Citation: Germain C, Vahanian A, Basquin A, Richoux-Benhaim C, Embouazza Hand Lejoyeux M (2011) Brief report: coronary heart disease: an unknown association to pathological gambling. Front. Psychiatry 2:11. doi: 10.3389/fpsyt.2011.00011

This article was submitted to Frontiers in Impulsivity, Compulsivity and Behavioral Dyscontrol, a specialty of Frontiers in Psychiatry.

Copyright (c) 2011 Germain, Vahanian, Basquin, Richoux-Benhaim, Embouazza and Lejoyeux. This is an open-access article subject to an exclusive license agreement between the authors and Frontiers Media $S A$, which permits unrestricted use, distribution, and reproduction in any medium, provided the original authors and source are credited. 